\title{
PERANCANGAN EIGRP ROUTING PROTOCOL UNTUK KONEKTIVITAS JARINGAN KOMPUTER PADA KANTOR CABANG BARU PT. AIA FINANCIAL
}

\author{
Irwan Satria ${ }^{1}$, Ade Surya Budiman², Sartini ${ }^{3}$ \\ 1,3Program Studi Teknik Informatika, STMIK Nusa Mandiri, Jakarta \\ 2Jurusan Teknologi Komputer, FTI, Universitas Bina Sarana Informatika, Jakarta \\ 1Irwansatria78@gmail.com, 2ade.aum@bsi.ac.id, ${ }^{3}$ sartini@nusamandiri.ac.id
}

\begin{abstract}
ABSTRAK
Abstrak, Jaringan internet saat ini telah menjadi salah satu kebutuhan utama dalam aktivitas manusia modern, sehngga layanan internet menjadi bagian dari pelayanan bagi fasilitas umum,konektivitas ini menjadi tuntutan bagi sebagian besar orang. PT.AIA Financial bergerak di bidang Asuransi yang tersebar di Indonesia. Kebutuhan akan komunikasi data sangat penting untuk menunjang kinerja berupa komunikasi data pada masing-masing cabang PT AIA Financial khususnya pemanfaatan teknologi komputer yang membutuhkan hubungan antar komputer dari lokasi yang berbeda.kondisi yang ada saat ini berjalan dengan baik menggunakan routing statis. Permasalahan yang ada saat ini adalah masing-masing kantor cabang dari PT.AIA Financial menggunakan routing statis untuk menghubungkan seluruh kantor cabang yang mana tidak fleksibel saat ada penambahan cabang baru dan adanya permintaan penambahan 5 kantor cabang baru. Peneliti menyarankan menggunakan dynamic routing EIGRP karena apabila ada penambahan cabang baru dari perusahaan akan lebih mudah dalam melakukan konfigurasinya dibandingkan dengan static routing yang digunakan saat ini. Ketika ada penambahan cabang baru, apabila menggunakan routing static maka administrator harus menambahkan route secara manual di setiap kantor cabang. Sedangkan apabila menggunakan routing dinamis maka administrator cukup menambahkan route secara manual hanya di cabang baru tersebut. Hasil saat menggunakan metode dinamis EIGRP pada pengujian sistem saat test ping pc ke router masing-masing kantor berjalan baik.
\end{abstract}

\section{Kata Kunci : EIGRP, Routing Dinamis, Kantor Cabang Baru, Route}

Abstract, The internet network is becoming a need of most people, so that internet service is part of the service for public facilities, this connectivity is a demand for most people. PT.AlA Financial is engaged in insurance which is spread in Indonesia. The need for data communication is very important to support performance in the form of data communication at each of PT AIA Financial's branches, especially the use of computer technology that requires connections between computers from different locations. The current conditions run well using static routing. The current problem is that each branch office of PT.AIA Financial uses static routing to connect all branch offices which are not flexible when there are additional new branches and requests for the addition of 5 new branch offices. The researcher recommends using EIGRP dynamic routing because if there are additional new branches from the company it will be easier to configure it compared to the static routing used today. When there are new branches added, when using static routing the administrator must add routes manually in each branch office. Meanwhile, if using dynamic routing, the administrator only needs to manually add routes in the new branch. The results when using the dynamic EIGRP method on system testing when the ping pc test to the routers of each office run well.

Keywords: EIGRP, Dynamic Routing, New Branch, Route 


\section{PENDAHULUAN}

Jaringan internet saat ini telah menjadi salah satu kebutuhan utama dalam aktivitas manusia modern, sehngga layanan internet menjadi bagian dari pelayanan bagi fasilitas umum. Infrastruktur jaringan komputer yang dirancang dan dibangun oleh suatu organisasi harus mampu memenuhi kebutuhan konektifitas yang diinginkan. Hanya dengan konektifitas yang baik, suatu jaringan komputer dapat memberikan manfaat bagi penggunanya, terkait dengan produktifitas dan kualitas pekerjaan.

Hal tersebut pula yang mendasari bahwa pengembangan infrastruktur jaringan komputer harus mampu mengikuti perkembangan organisasi atau perusahaan dimana jaringan komputer tersebut dibangun. Tanpa infrastruktur jaringan komputer yang memadai, pengembangan wilayah bisnis suatu organisasi atau perusahaan juga tidak akan optimal, dikarenakan minimnya interkoneksi antar wilayah. Interkoneksi jaringan komputer antar wilayah membutuhkan keberadaan Router sebagai simpul penghubung antara satu jaringan dengan jaringan lainnya, baik jaringan internal perusahaan maupun antar institusi atau antar perusahaan. Router mempelajari informasi routing dari mana sumber dan tujuan data, dan menyimpannya di routing table, untuk kemudian menggunakannya untuk menentukan rute dari sumber ke tujuan data tersebut.

Mekanisme interkoneksi lintas jaringan dengan menggunakan Router dalam proses penerusan data (data forwarding) dari satu Router ke Router lainnya dalam jaringan didefinisikan sebagai Routing Protocol.

Untuk interkoneksi antar Router dalam suatu jaringan yang kompleks dan besar, dibutuhkan Dynamic Routing Protocol. Informasi routing dipelajari oleh Router dari Router yang lain atau Router "tetangganya" [7]. Fleksibilitas, Kehandalan dan Kecepatan menjadi karakteristik yang diharapkan dari suatu Dynamic Routing Protocol. Routing Information Protocol (RIP), Open Shorthest Path First (OSPF) dan Enhanced Interior Gateway Routing Protocol (EIGRP), merupakan tiga diantara beberapa Routing Protocol yang dapat digunakan untuk menghubungkan jaringan-jaringan antar wilayah yang luas dan berjauhan.
Setiap Protocol Routing memiliki kelebihan dan keunggulan masing-masing, mengingat algoritma yang dipakai pada setiap protocol memiliki perbedaan. Seperti misalnya dalam penentuan jalur terbaik (best path) untuk menuju ke suatu jaringan, RIP menggunakan hop counts, Interior Gateway Routing Protocol (IGRP) dan EIGRP menggunakan sebuah composite metric dari Bandwidth, Reliability, Load, Delay dan ukuran MTU, sedangkan OSPF menggunakan cost metric [6].

Perlu penyesuaian dalam pemilihan Routing Protocol yang tepat bagi sebuah jaringan komputer. Penyesuaian bisa dengan mengacu kepada permasalahan, topologi dan skema pada suatu perusahaan atau organisasi yang ingin menerapkannya.

PT.AIA Financial merupakan perusahaan yang bergerak di bidang Asuransi, dengan kantor cabang perusahaan yang tersebar di beberapa wilayah di Indonesia. Kebutuhan akan komunikasi data sangat penting untuk menunjang kinerja berupa komunikasi data transaksi dan data nasabah yang ada di masing-masing cabang.

Permasalahan yang ada saat ini adalah masing-masing kantor cabang dari PT.AIA Financial menggunakan routing statis untuk menghubungkan seluruh kantor cabang yang mana tidak fleksibel saat ada penambahan kantor cabang baru dan adanya permintaan penambahan 5 kantor cabang baru di beberapa lokasi di Jakarta, yaitu Kelapa Gading, Gatot Subroto, Green Garden, Rasuna Said dan Pasar Manggis. Penulis menyarankan menggunakan dynamic routing, dengan pertimbangan apabila ada penambahan cabang baru dari perusahaan akan lebih mudah dalam melakukan konfigurasinya dibandingkan dengan static routing yang digunakan saat ini. Ketika ada penambahan cabang baru, apabila menggunakan static routing maka administrator harus menambahkan route secara manual di setiap kantor cabang. Sedangkan, apabila menggunakan dynamic routing maka administrator cukup menambahkan route secara manual hanya di cabang baru tersebut.

Telah cukup banyak penelitian yang membandingkan unjuk kerja antara dynamic routing yang satu dengan dynamic routing yang lain. Diantaranya memperoleh hasil yang terkait dengan throughput dan load, EIGRP dan OSPF memiliki efisiensi yang lebih baik dibandingkan 
dengan RIP dan IGRP, berdasarkan hasil simulasi menggunakan OPNET Simulator, sehingga EIGRP dan OSPF tepat diterapkan pada perusahaan besar, institusi pendidikan dan lokasi industri [3]. EIGRP memiliki konvergensi yang lebih baik daripada OSPF, disamping juga memiliki nilai Point to Point Queuing Delay yang lebih rendah dibandingkan OSPF [2].

Dengan menggunakan parameter pengujian terkait Quality of Service (QoS) pada aplikasi Voice over Internet Protocol (VolP) untuk membandingkan EIGRP dan OSPF. Kinerja yang lebih baik diberikan oleh EIGRP terkait dengan waktu konvergensi [4]. Kendati demikian, terdapat hasil berbeda ketika mengukur QoS pada beban pengiriman audio dan video, dengan menggunakan aplikasi Wireshark, diperoleh nilai Throughput, Delay dan Packet Loss yang lebih kecil pada OSPF, dibandingkan dengan EIGRP [5].

EIGRP memiliki fitur back up route, dimana jika terjadi perubahan pada network, EIGRP memberikan tabel routing terbaik, selain itu EIGRP juga menyimpan backup terbaik untuk setiap route, sehingga setiap kali terjadi kegagalan pada jalur utama, maka EIGRP menawarkan jalur alternatif tanpa menunggu waktu convergence [8].

EIGRP memanfaatkan prinsip distance vector dan link-state, sehingga routing ini bisa disebut Hybrid Distance Vector Routing Protocol. Artinya dalam menentukan jalur terbaik, routing ini menggunakan asumsi jalur terpendek dan metric cost. Teknik Metric cost memanfaatkan nilai dari jalur berdasarkan delay, atau juga bisa dengan bandwidth [1].

Dengan pertimbangan yang mengacu kepada hasil-hasil penelitian terdahulu, maka dalam penelitian ini, penulis akan menguji sejauh mana efektifitas pemanfaatan EIGRP untuk membangun interkoneksi jaringan lintas wilayah pada PT. AIA Financial.

\section{METODE PENELITIAN}

\subsection{Metode Pengembangan jaringan}

Dengan lingkup penelitian yang hanya sampai kepada tahap perencanaan, maka penelitian ini dibagi atas sejumlah tahapan yaitu:

a. Analisa kebutuhan

Penulis menganalisa kebutuhan yang
dibutuhkan dalam melakukan jaringan komunikasi data yang akan digunakan 1 buah Swich, Router dan PC di cabang baru PT.AIA Financial. Kebutuhan interkoneksi jaringan adalah agar dapat menjembatani komunikasi data antara kantor cabang yang ada dengan kantor cabang yang baru, jika kantor-kantor cabang yang baru akan dibuka.

b. Desain

Penulis mendesain sistem sesuai dengan masalah yang ada pada PT.AIA Financial. Desain dilakukan dengan menggunakan aplikasi simulator Cisco Packet Tracer.

c. Pengujian

Penulis melakukan pengujian jaringan untuk komunikasi data antar kantor cabang dengan mengakses dan mengirim data, dengan menggunakan aplikasi simulasi Cisco Packet Tracer.

\subsection{Metode Pengumpulan Data}

a. Observasi

Observasi menggunakan metode pengumpulan data yang di lakukan dengan cara pengamatan secara langsung terhadap prosedur kerja dan sistem jaringan yang berjalan di PT. AIA Financial.

b. Wawancara

Wawancara dilakukan dengan cara berdiskusi secara langsung mengenai objek jaringan komputer PT. AIA Financial dan permasalahan yang terkait. Wawancara dilakukan dengan Manager IT pada PT.AIA Financial.

\section{HASIL DAN PEMBAHASAN}

\subsection{Topologi Existing Network}

Topologi jaringan merupakan hal yang paling mendasar dalam membentuk sebuah jaringan. Untuk existing network, topologi jaringan yang digunakan pada perusahaan saat ini seperti ditunjukkan dalam gambar 1. Jaringan saat ini menghubungkan Kantor Cabang Sudirman, Fatmawati dan Mampang. 


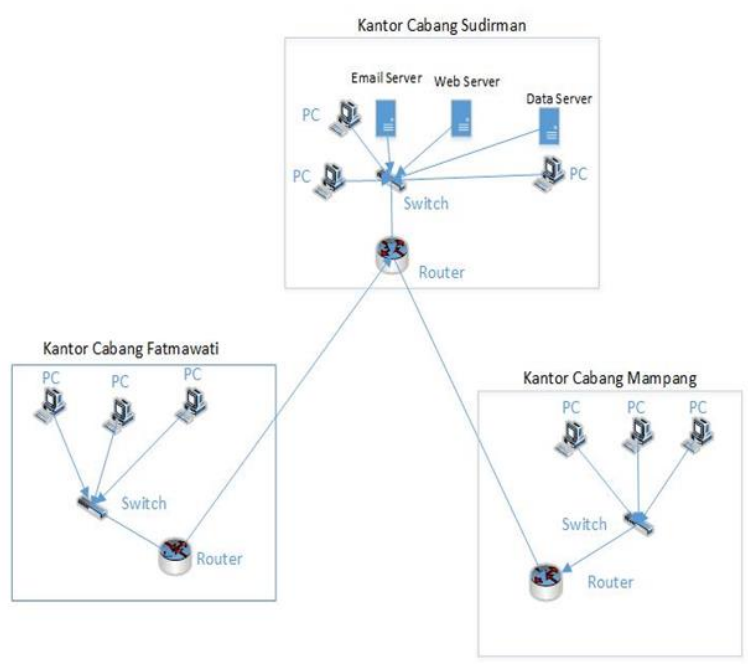

Gambar 1. Existing Network

Berdasarkan topologi jaringan berjalan, Kantor cabang Sudirman memiliki tiga server penting yaitu Email, Web dan Data Server, yang harus bisa diakses dari kantor cabang yang lain.

Sebagaimana telah dibahas sebelumnya, permasalahan kompleksitas dan fleksibilitas akses data akan terjadi ketika dibutuhkan akses data dari kantor-kantor cabang yang baru, tanpa harus mengkonfigurasi ulang jaringan secara keseluruhan, sebagaimana yang terjadi pada konsep static routing.

\subsection{Skema Jaringan Usulan}

a. Jaringan Usulan

Mengacu kepada permasalahan yang yang

telah disampaikan, terkait dengan rencana penambahan kantor-kantor cabang baru, dalam skema jaringan yang diusulkan akan diujicobakan untuk menambahkan 5 kantor cabang baru.

Dengan mempertimbangkan fleksibilitas yang dimiliki oleh dynamic routing protocol, maka semestinya penambahan jaringan kantor cabang tidak akan terbatasi oleh kompleksitas dan ukuran jaringan.

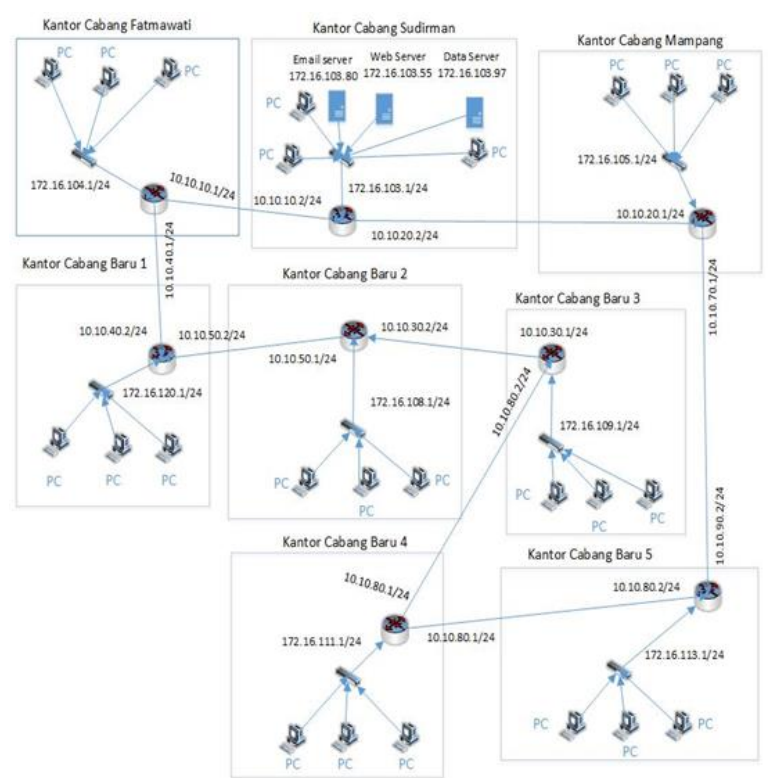

Gambar 2. Skema Jaringan Usulan

b. Desain Jaringan Usulan

Pada tahap ini dilakukan desain untuk implementasi Dynamic Routing EIGRP. Desain jaringan dibuat pada simulator Cisco Packet Tracer. Dalam gambar 3, diperlihatkan hasil desain perencanaan jaringan ketika diterapkan Dynamic Routing EIGRP.

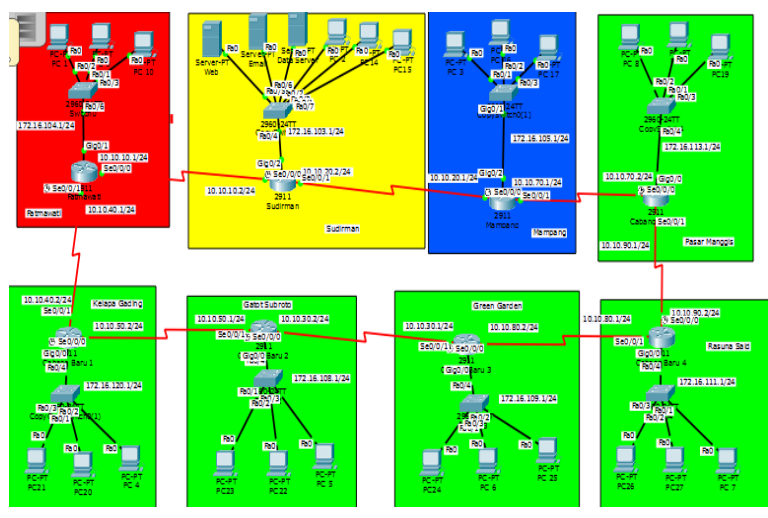

Gambar 3. Desain Jaringan Usulan

c. Konfigurasi Jaringan Usulan

Berikutnya adalah pembuatan konfigurasi pada Router yang terdapat pada masing-masing kantor cabang, baik kantor cabang existing maupun rencana kantor cabang baru.

\section{Kantor Cabang Fatmawati}

Router\#en 
Router\#conf $t$

Enter configuration commands, one per line. End with CNTL/Z.

Router(config)\#hostname fatmawati

fatmawati(config)\# interface gigabitEthernet 0/1

fatmawati(config-if)\#ip add 172.16.104.1

255.255.255.0

fatmawati(config-if)\#no shutdown

fatmawati(config-if)\#int gig 0/0

fatmawati(config-if)\#ip add 10.10.10.1

255.255.255.0

fatmawati(config-if)\#no shutdown

fatmawati(config-if)\#

fatmawati(config-if)\#end

fatmawati\#conf $\mathrm{t}$

Enter configuration commands, one per line.

End with CNTL/Z.

Fatmawati(config)\#router eigrp 10

fatmawati(config-router)\#network 10.10.10.2

fatmawati(config-router)\#no auto-summary

fatmawati(config-router)\#end.

\section{Kantor Cabang Sudirman \\ Router>en \\ Router\#conf $t$ \\ Enter configuration commands, one per line. \\ End with CNTL/Z. \\ Router(config)\#hostname sudirman \\ sudirman(config)\#int gig 0/2 \\ sudirman(config-if)\#ip add 172.16.103.1 \\ 255.255.255.0 \\ sudirman(config-if)\#no shutdown \\ sudirman(config-if)\#int gig 0/0 \\ sudirman(config-if)\#ip add 10.10.10.2 \\ 255.255.255.0 \\ sudirman(config-if)\#no shutdown \\ sudirman(config-if)\#int gig 0/1 \\ sudirman(config-if)\#ip add 10.10.20.2 \\ 255.255.255.0 \\ sudirman(config-if)\#no shutdown \\ sudirman(config-if)\#end \\ sudirman\#en \\ sudirman\#conf $\mathrm{t}$ \\ Enter configuration commands, one per line. \\ End with CNTL/Z. \\ Sudirman(config)\#router eigrp 10 \\ sudirman(config-router)\#network 10.10.10.1 \\ sudirman(config-router)\#network 172.16.104.1 \\ sudirman(config-router)\#no auto-summary \\ sudirman(config-router)\#end}

\section{Kantor Cabang Mampang}

Router>en

Router\#conf $\mathrm{t}$

Enter configuration commands, one per line.

End with CNTL/Z.

Router(config)\#hostname mampang

mampang(config)\#int gig 0/2

mampang(config-if)\#ip add 172.16.105.1

255.255.255.0

mampang(config-if)\#no shutdown

mampang(config-if)\#int gig 0/0

mampang(config-if)\#ip add 10.10.30.2

255.255.255.0

mampang(config-if)\#no shutdown

mampang(config-if)\#int gig 0/1

mampang(config-if)\#ip add 10.10.20.1

255.255.255.0

mampang(config-if)\#no shutdown

mampang(config-if)\#end

mampang\#en

mampang\#conf $t$

Enter configuration commands, one per line.

End with CNTL/Z.

Mampang(config)\#router eigrp 10

mampang(config-router)\#network 10.10.20.2

mampang(config-router)\#network 172.16.103.1

mampang(config-router)\#no auto-summary

mampang(config-router)\#end

\section{Kantor Cabang Kelapa Gading}

Router>en

Router\#conf $\mathrm{t}$

Enter configuration commands, one per line.

End with CNTL/Z.

Router(config)\#hostname kelapa_gading

kelapa_gading(config)\#int gig 0/0

kelapa_gading(config-if)\#ip add 172.16.120.1

255.255.255.0

kelapa_gading(config-if)\#no shutdown

kelapa_gading(config-if)\#int gig 0/1

kelapa_gading(config-if)\#ip add 10.10.30.1

255.255.255.0

kelapa_gading(config-if)\#no shutdown

kelapa_gading(config-if)\#int gig 0/2

kelapa_gading(config-if)\#ip add 10.10.50.2

255.255.255.0

kelapa_gading(config-if)\#no shutdown

kelapa_gading(config-if)\#end

kelapa_gading\#en

kelapa_gading\#conf $t$

Enter configuration commands, one per line.

End with CNTL/Z.

Kelapa_gading(config)\#router eigrp 10 
kelapa_gading(config-router)\#network 10.10.30.2

kelapa_gading(config-router)\#network

172.16.105.1

kelapa gading(config-router)\#no auto-summary

kelapa_gading(config-router)\#end

\section{Kantor Cabang Gatot Subroto}

Router>en

Router\#conf $t$

Enter configuration commands, one per line.

End with CNTL/Z.

Router(config)\#hostname gatot_subroto

gatot_subroto(config)\#int gig 0/2

gatot_subroto(config-if)\#ip add 10.10.70.2

255.255.255.0

gatot_subroto(config-if)\#no shutdown

gatot_subroto(config-if)\#int gig 0/0

gatot_subroto(config-if)\#ip add 172.16.108.1

255.255.255.0

gatot_subroto(config-if)\#no shutdown

gatot_subroto(config-if)\#int gig 0/1

gatot_subroto(config-if)\#ip add 10.10.50.1

255.255.255.0

gatot_subroto(config-if)\#no shutdown

gatot_subroto(config-if)\#end

gatot_subroto\#en

gatot_subroto\#conf $t$

Enter configuration commands, one per line.

End with CNTL/Z.

Gatot_subroto(config)\#router eigrp 10

gatot_subroto(config-router)\#network 10.10.50.2

gatot_subroto(config-router)\#network

172.16.120.1

gatot_subroto(config-router)\#no auto-summary

gatot_subroto(config-router)\#end

\section{Kantor Cabang Green Garden}

Router>en

Router\#conf $t$

Enter configuration commands, one per line.

End with CNTL/Z.

Router(config)\#hostname green_garden

green_garden(config)\#int gig 0/2

green_garden(config-if)\#ip add 10.10.80.2

255.255.255.0

green_garden(config-if)\#no shutdown

green_garden(config-if)\#int gig 0/0

green_garden(config-if)\#ip add 172.16.109.1

255.255.255.0

green_garden(config-if)\#no shutdown

green_garden(config-if)\#int gig 0/1 green_garden(config-if)\#ip add 10.10.70.1

255.255.255.0

green_garden(config-if)\#no shutdown

green_garden(config-if)\#end

green_garden\#en

green_garden\#conf $t$

Enter configuration commands, one per line.

End with CNTL/Z.

Green_garden(config)\#router eigrp 10

green_garden(config-router)\#network 10.10.70.2

green_garden(config-router)\#network

172.16.108.1

green_garden(config-router)\#no auto-summary

green_garden(config-router)\#end

\section{Kantor Cabang Rasuna Said}

Router>en

Router\#conf $t$

Enter configuration commands, one per line.

End with CNTL/Z.

Router(config)\#hostname rasuna_said

rasuna said(config)\#int gig 0/2

rasuna_said(config-if)\#ip add 10.10.90.2

255.255.255.0

rasuna_said(config-if)\#no shutdown

rasuna_said(config-if)\#int gig 0/0

rasuna_said(config-if)\#ip add 172.16.111.1

255.255.255.0

rasuna said(config-if)\#no shutdown

rasuna_said(config-if)\#int gig 0/1

rasuna_said(config-if)\#ip add 10.10.80.1

255.255.255.0

rasuna_said(config-if)\#no shutdown

rasuna_said(config-if)\#end

rasuna said\#en

rasuna_said\#conf $t$

Enter configuration commands, one per line.

End with CNTL/Z.

Rasuna_said(config)\#router eigrp 10

rasuna_said(config-router)\#network 10.10.80.2

rasuna_said(config-router)\#network

172.16.109.1

rasuna_said(config-router)\#no auto-summary

rasuna_said(config-router)\#end

\section{Kantor Cabang Pasar Mangqis}

Router>en

Router\#conf $\mathrm{t}$

Enter configuration commands, one per line.

End with CNTL/Z.

Router(config)\#hostname pasar_manggis

pasar_manggis(config)\#int gig $0 / 0$ 
pasar_manggis(config-if)\#ip add 172.16.113.1 255.255.255.0

pasar_manggis(config-if)\#no shutdown

pasar_manggis(config-if)\#int gig 0/1

pasar_manggis(config-if)\#ip add 10.10.90.1

255.255.255.0

pasar_manggis(config-if)\#no shutdown

pasar_manggis(config-if)\#end

pasar_manggis\#en

pasar_manggis\#conf $t$

Enter configuration commands, one per line.

End with CNTL/Z.

Pasar_manggis(config)\#router eigrp 10

pasar_manggis(config-router)\#network

10.10.90.2

pasar_manggis(config-router)\#network

172.16.111.1

pasar_manggis(config-router)\#no auto-summary

pasar_manggis(config-router)\#end

\section{d. Pengujian Jaringan}

Dalam tahapan pengujian jaringan, uji konektivitas antar kantor cabang dilakukan dengan menggunakan uji pengiriman Ping. Dalam Gambar 4 diperlihatkan sebagian dari hasil uji konektivitas ketika masih menggunakan static routing, yaitu antara kantor cabang Mampang dengan kantor cabang Sudirman.

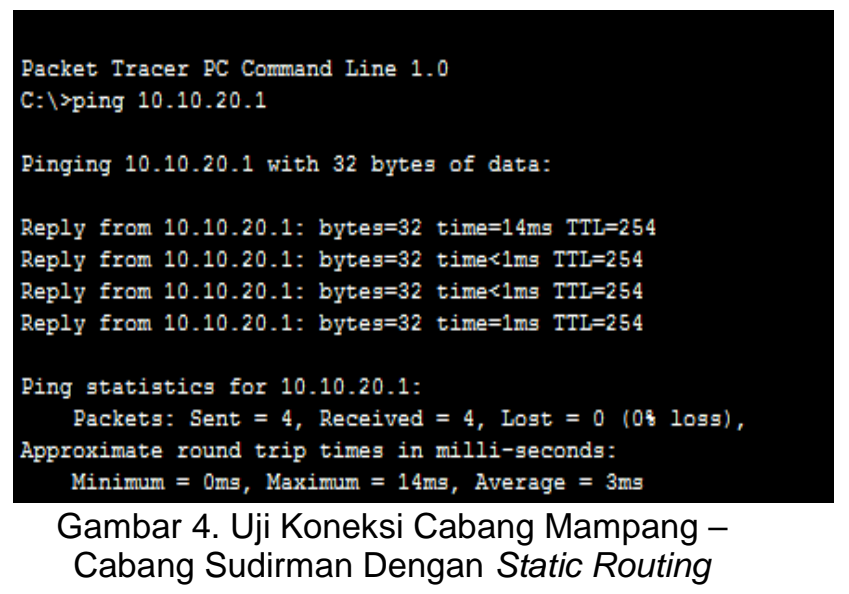

Secara keseluruhan, seluruh kantor cabang dapat terhubung/terkoneksi dengan baik, dengan menggunakan static routing. Akan tetapi permasalahan yang akan diselesaikan bukan hanya sebatas konektivitas, namun terkait dengan fleksibilitas manajemen jaringan yang kompleks dan luas.
Selanjutnya, setelah dilakukan desain dan konfigurasi pada setiap Router di masing-masing kantor cabang, dilakukan uji koneksi dengan cara yang sama, yaitu dengan melakukan uji Ping.

Dalam gambar 5 , diperlihatkan sebagian dari proses uji konektivitas antar kantor-kantor cabang. Dalam gambar tersebut, diperlihatkan proses uji konektivitas data dari kantor cabang Fatmawati ke kantor cabang Kelapa Gading, dimana setiap Router di setiap kantor cabang telah diberikan konfigurasi dynamic routing.

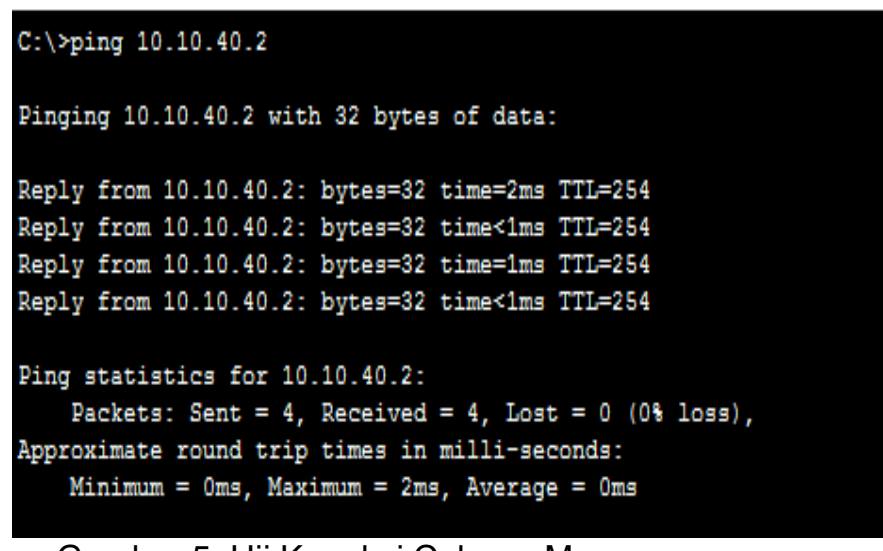

Gambar 5. Uji Koneksi Cabang Mampang Cabang Sudirman Dengan Dynamic Routing

Hasil yang sama berupa koneksi yang berhasil dibentuk antar kantor cabang, baik kantor cabang lama maupun kantor cabang baru, juga ditemukan dari hasil pengujian lainnya yang dilakukan oleh penulis.

Ringkasan hasil pengujian, baik pada static routing maupun pada dynamic routing diperlihatkan didalam gambar 6 dan 7 .

Hasil Test Ping menggunakan metode Routing Static

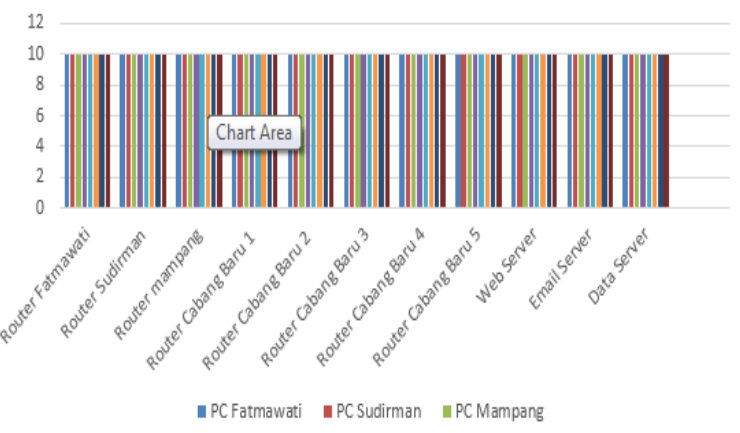


Gambar 6. Ringkasan Hasil Pengujian

Menggunakan Static Routing

Hasil Test Ping menggunakan metode dinamis eigrp

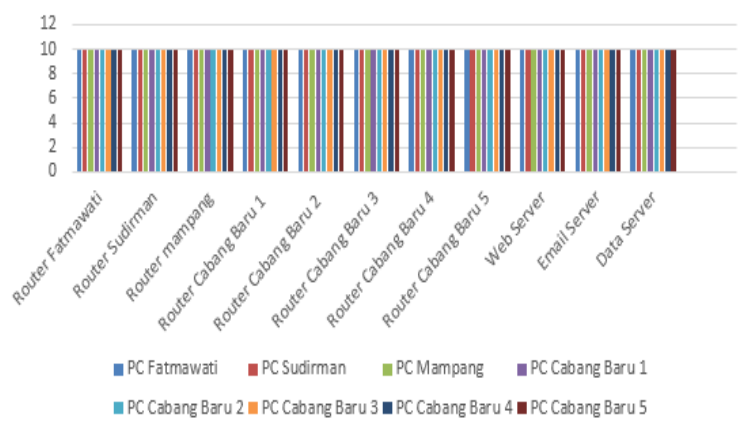

Gambar 7. Ringkasan Hasil Pengujian Menggunakan Dynamic Routing

\section{KESIMPULAN DAN SARAN}

Dari hasil analisa dan pengujian dapat disimpulkan bahwa dengan menggunakan dynamic routing EIGRP untuk penambahan cabang baru dari perusahaan, akan lebih mudah dalam melakukan konfigurasinya dibandingkan dengan static routing. Administrator jaringan cukup menambahkan route secara manual hanya di kantor cabang baru, tanpa melakukan rekonfigurasi di kantor cabang lama atau existing network.

Selanjutnya untuk memperkuat keamanan jaringan komputer perusahaan dengan menggunakan otentikasi, agar saat masuk ke router setiap cabang, dimana apabila ada koneksi baru harus melakukan otentikasi untuk memastikan bahwa perangkat yang terhubung benar. Terkait dengan adanya penambahan cabang baru, perusahaan dapat juga membuat server di lokasi cabang baru untuk memback up apabila terjadi kendala pada server utama di kantor cabang Sudirman.

\section{DAFTAR PUSTAKA}

[1] Al Ghivani, A. Z. (2018). Studi Perbandingan Routing Protokol BGP Dan EIGRP, Evaluasi Kinerja Performansi Pada Autonomous System Berbeda. Jurnal Sistemasi, 7, 95105.

[2] Georgina, O. N., Chukwuchebe, O. H., \& Rosemary, D. M. (2018). Simulation Based Appraisal Study Of OSPF And EIGRP For
Effective Communication. FUDMA Journal of Sciences (FJS), 2(1), 89-98.

[3] Kalamani, P., Kumar, M. V., Chithambarathanu, M., \& Thomas, R. (2014). Comparison of RIP , EIGRP , OSPF , IGRP Routing Protocols in Wireless Local Area Network ( WLAN ) by using OPNET Simulator tool - A Practical Approach. IOSR Journal of Computer Engineering (IOSRJCE), 16(4), 57-64.

[4] Maryati, L. D., Primananda, R., \& Ichsan, M. H. H. (2017). Analisis Kinerja Protokol Routing OSPF dan EIGRP Untuk Aplikasi VolP Pada Topologi Jaringan Mesh. Jurnal Pengembangan Teknologi Informasi Dan IImu Komputer, 1(9), 960-970.

[5] Novendra, Y., Arta, Y., \& Siswanto, A. (2018). Analisis Perbandingan Kinerja Routing OSPF Dan EIGRP. IT Journal Research and Development, 2(2), 97-106.

[6] Patel, H. N., \& Pandey, R. (2014). Extensive Reviews of OSPF and EIGRP Routing Protocols based on Route Summarization and Route Redistribution. Int. Journal of Engineering Research and Applications, 4(9), 141-144.

[7] Purwanto, T. D. (2018). Analisis Kinerja Dynamic Routing pada Protokol Routing EIGRP untuk Menentukan Jalur Terbaik dengan Diffusing Update Algorithm (DUAL). JUITA : Jurnal Informatika, 6(2), 89-98.

[8] Syukur, A., \& Julianti, L. (2018). Simulasi Pemanfaatan Dynamic Routing Protocol EIGRP Pada Router di Jaringan Universitasi Islam Riau Beserta Autentikasinya. Jurnal Teknologi Informasi Dan IImu Komputer, $5(1)$, 23. https://doi.org/10.25126/jtiik.201851535 